\title{
Coordinated hunting behaviors of mixed-species groups of piscivores and associated species at Isla del Coco National Park (Eastern Tropical Pacific)
}

\author{
Peter J. Auster ${ }^{1,2}$, Jorge Cortés ${ }^{3,4}$, Juan José Alvarado ${ }^{3,4}$ and Andrés Beita-Jiménez $3,4,5$
}

Studies of mixed-species groups of animals can reveal emergent complexities of collective behaviors. In this study we collected data on mixed-species hunting groups composed primarily of piscivorous fishes (species composition, abundance, behavioral interactions) and used both multivariate and network analyses to quantify pair-wise and guild level behavioral relationships. Our results indicate that such collective behaviors exhibit consistent patterns of associations (33 species with 282 pair-wise links within the observed network) with 10 dominant species accounting for $60 \%$ of pair-wise interactions. Species richness within groups varied (mean $=2.4$, range 2-6 species) as did group size (mean $=8.1$ individuals, range 2-80). Mixed-species groups, in general, were composed of species representing morphologically diverse forms that appeared to enhance access to shelter sites and implement diverse strategies for prey capture. It is noteworthy that the composition of groups did not reflect the relative abundances of their component species within the overall community of fishes, suggesting that group membership was an elective choice. The identification of these patterns, assuming they are persistent features of these communities, can be used as a foundation for studies to assess dynamics of mixed-species relationships, rates of predator success based on group membership, demographic consequences, and responses to variations in habitat attributes and associated prey resources. Such information could be used to interpret the nature of multispecies interactions within predator communities and potentially aid in conservation and management.

Keywords: Facilitation, Marine protected area, Mutualism, Network, Predation.

Estudios de grupos mixtos de animales puede revelar complejidades y sutilezas del comportamiento colectivo. En este estudio recolectamos datos sobre depredación de grupos mixtos de especies, compuestos principalmente por piscívoros (composición de especies, abundancia, interacciones) y usamos tanto análisis multivariado como de redes para cuantificar relaciones de comportamiento entre pares de especies y a nivel de gremios. Nuestros resultados indican que los comportamientos colectivos exhiben patrones consistentes de asociaciones (33 especies con 382 interacciones entre pares de especies dentro de la red) con 10 especies dominantes que constituyen el $60 \%$ de las interacciones entre dos especies. La riqueza de especies dentro de grupos varió (media = 2.4, ámbito 2-6 especies) cómo también el tamaño del grupo (media = 8.1, ámbito 2-80). Los grupos de especies mixtas, en general, estaban compuestos por especies con diversas morfologías que aparentemente aumentan el accesos a lugares estrechos y además, implementa diversas estrategias de captura de presas. Vale la pena resaltar que la composición de los grupos no reflejaba la abundancia relativa de las especies en la comunidad total de peces, sugiriendo que la membresía en el grupo era algo electivo. La identificaión de estos patrones, asumiendo que son características persistentes de la comunidad, se podrán usar en estudios para determinar la dinámica de las relaciones de grupos mixtos, tasa de éxito de depredación basado en la membresía del grupo, consecuencias demográficas y respuestas a varicaciones en las habitat y presas. Esta información servirá para interpretar la naturaleza de las interacciones multiespecíficas dentro de la comunidad de depredadores y potencialmente ayudar en la conservación y manejo de recursos.

Palabras clave: Área marinas protegidas, Depredación, Facilitación, Mutualismo, Red.

\footnotetext{
${ }^{1}$ University of Connecticut, Department of Marine Sciences, 1080 Shennecossett Rd., Groton, Connecticut 06340 USA. peter. auster@uconn.edu, Dhttps://orcid.org/0000-0002-6023-2829 (corresponding author)

${ }^{2}$ Mystic Aquarium - Sea Research Foundation, 55 Coogan Blvd., Mystic, Connecticut 06355 USA. pauster@mysticaquarium.org ${ }^{3}$ Centro de Investigación en Ciencias del Mar y Limnología (CIMAR), Ciudad de la Investigación, Universidad de Costa Rica, San Pedro, 11501-2060 San José, Costa Rica. (JC) jorge.cortes@ucr.ac.cr, Ohttps://orcid.org/0000-0001-7004-8649; (JJA) juanalva76@yahoo.com, (Dhttps://orcid.org/0000-0002-2620-9115

${ }^{4}$ Escuela de Biología, Universidad de Costa Rica, San Pedro, 11501-2060 San José, Costa Rica.

${ }^{5}$ Center for Fisheries Ecosystem Research, Fisheries and Marine Institute, Memorial University of Newfoundland, Canada. (ABJ) abeitaj@gmail.com, Ohttps://orcid.org/0000-0002-0104-8183
} 


\section{Introduction}

Studies of the consequences of mixed-species group behavior (with much work focused on mammals, birds, and insects) have been fundamental to our understanding of the ecological role that such interactions play in terms of enhancement of individual fitness (Dickman, 1992; Sumpter, 2010). Group behaviors are considered a form of facilitation when encounters between organisms benefit at least one in a pair-wise species interaction but cause harm to neither (commensalism), or a mutualism when both species derive a benefit from the interaction (Connor, 1995; Stachowicz, 2001; Bruno et al., 2003). For example, variation in the size and composition of species within foraging groups can enhance efficiency in location of food patches by accessing concealed prey in novel locations and enhance vigilance in identifying predation threats based on variation in sensory abilities (Krause, Ruxton, 2002). From the perspective of higher trophic level predators, cooperation within mixed-species groups can enhance predation success and reduce energetic costs of search (Hebshi et al., 2008). Such interactions among individuals within groups can result in positive population-level effects such as enhanced growth and fecundity (Firth et al., 2015).

In marine fishes, decades of study have been devoted to understanding the ecological consequences of single species group behaviors, primarily those that school or aggregate for feeding, predator refuge, or for reproduction (Pitcher, Parrish, 1993; Kelley et al., 2011). Much less attention has been paid to the behavior of mixed-species groups, especially those that are short term, and the resultant ecological consequences (but see Lukoschek, McCormick, 2002; Sazima et al., 2010). Previous studies have focused on how group foraging enhances the fitness of individuals (Overholtzer, Motta, 2000) and how such interactions are linked to community composition and patterns of diversity (Auster, Lindholm, 2002, 2008). We find that these types of collective behaviors are common attributes of fish communities, most notably those associated with reef features where types and rates of interactions between species are greater (Hobson, 1968; Auster et al., 2013).

Given the role that higher trophic level predators play in structuring marine communities (O'Connor, Bruno, 2007; Heithaus et al., 2008; Sandin et al., 2008; Estes et al., 2011), studies of the collective behaviors of reef piscivores ultimately may provide increased detail on how such interactions within this trophic guild shape the dynamics of both predator and prey populations (Sih et al., 1998; Lima, 2002; Berger-Tal et al., 2011). However, today we remain at a stage where simple but detailed descriptions are needed of the diversity of species interactions, within diverse ecological settings, to provide insight into the range of potential pair-wise responses. Here we describe the web of behaviors exhibited by mixed-species hunting groups of piscivores at Isla del Coco National Park, Costa Rica, in the Eastern Tropical Pacific (ETP), where a recent study concluded that the shallow waters around the island have the highest density of apex predators within the ETP (Friedlander et al., 2012; Alvarado et al., 2016). Such a predator-rich location makes this protected area an ideal natural laboratory to study the interactions of predatory reef fishes in the absence of direct human impacts.

We used approaches from network analysis for quantifying attributes of behavior webs, identified a subset of species that are dominant within the network structure, and discuss the implications of such behavior webs in the ecology of fish communities and for addressing conservation objectives. We suggest that this fish community can serve as a reference for studies of species interactions in the absence of proximate fishing pressure and other chronic human activities in the ETP.

\section{Material and Methods}

Isla del Coco is located approximately $550 \mathrm{~km}$ south-west of the Costa Rican mainland (Fig. 1). The island and surrounding waters out to $22.2 \mathrm{~km}$, covering an area of 1989 $\mathrm{km}^{2}$, constitute a National Park. The isolated $24 \mathrm{~km}^{2}$ island is primarily forested with minimal land cover alteration (to support a limited number of park personnel) so there is relatively low sediment load from runoff onto surrounding marine habitats. Limited moorings and areas of allowable anchorage reduce tourism and attendant impacts both on the island and in the water. The marine unit of the park that surrounds the island was designated in 2001 as a no-fishing zone and is well enforced (Cortés, 2016).

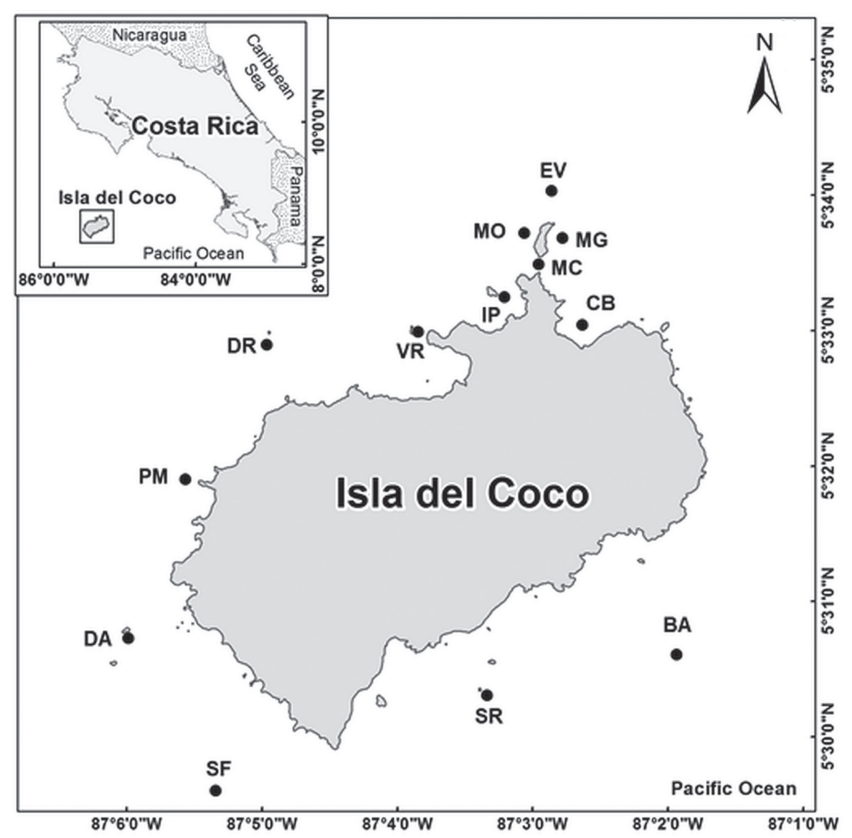

Fig. 1. Location map. $B A=$ Bajo Alcyone, $D A=B i g$ Dos Amigos, $\mathrm{CB}=$ Chatham Bay, DR = Dirty Rock, EV = Everest, $\mathrm{IP}=$ Isla Pájara, $\mathrm{MC}=$ Manuelita Channel, $\mathrm{MG}=\mathrm{Ma}-$ nuelita Coral Garden, $\mathrm{MO}=$ Manuelita Outside, $\mathrm{PM}=$ Punta María, SF $=$ Shark Fin Rock, SR $=$ Submerge Rock, VR = Viking Rock. 
Data were collected using direct underwater observation approaches during two cruises conducted from 1-11 February 2014 (MV Sea Hunter) and 24 February - 6 March 2015 (MV Argo). A modified roving diver transect (sensu Schmitt, Sullivan, 1996) was employed to survey behavioral interactions of piscivores and associated species at each station (Fig. 1). SCUBA was employed during 111 person-dives at 39 dive stations between 10 and $35 \mathrm{~m}$ depth, for a total dive time of $188 \mathrm{~h}$ (inclusive of 2-4 divers on each dive). The submersible vehicle DeepSee (Cortés, Blum, 2008) was used for an additional two dives using the same sampling protocol (Starr et al., 2012; Auster et al., 2016) to extend observations to the 50-80 m depth range for an additional $2.4 \mathrm{~h}$.

During all survey dives data were collected on the interactions between piscivores and potential prey (species identification to lowest possible taxon, number of individuals, and behavioral attributes related to the elements of predation, from search to prey capture), as well as for associated species that modified predator-prey interactions, for each predation event. Divers paused along transects to observe predation related events as they were identified and continued only after a) events ended and predators dispersed or b) groups of fishes involved in each event moved beyond the range of visibility. Primary data were recorded on dive slates, while still photographic and video imagery served to confirm and clarify species and interactions as well as document surrounding habitats. Multiple observers worked different areas and depths during each dive and debriefed post dive to avoid duplicate sets of observations.

Fishes that exhibited predation related behaviors had the following characteristics: (1) two or more fishes exhibited at least one of the sequential components of predatory behaviors, including search, approach, attack, and capture (sensu MacNulty et al., 2007); (2) individuals exhibited non-linear swimming and oriented toward potential prey or their shelter sites; and (3) animals moved as a group. Attack and prey capture were not required for an event to be recorded. Each predation related event and associated group composition was treated as a single sample unit.

Cumulative species richness across samples and richness estimator approaches, both Michaelis-Menton and Chao 1 (Clarke, Warwick, 2001), calculated using Primer version 6.1.13 software (Clarke, Gorley, 2006), were used to assess the adequacy of sampling. Descriptive statistics and graphical visualization were used to assess variation in group size and species richness of piscivores across predation events. Network analysis using SOCPROG software v2.6 (Whitehead, 2009) was used to assess the variability in pair-wise species linkages and associations across the network of behavioral interactions. Measures of mixed-species pair-wise links, total occurrences (of mixed-species links) across events, network strength, and eigenvector centrality were calculated to compare and contrast the role of particular species in hunting groups. Mixed-species links were quantified as the total number of pair-wise associations for each species and were independent of the number of such interac- tions (e.g., species A with species B is one link regardless of the number of times this occurred). Total occurrences across events was the total number of instances across all events that each species was associated with any other species. Indication of presence-absence in single species groups $(\geq$ 3 individuals) was a simple indicator of whether each taxa also hunted in monospecific groups. Network strength was the sum of associations of any species with all other species (Barrat et al., 2004). Eigenvector centrality was a measure not only of how strongly a species was associated to another species, but also the strength of the association of that species to others (e.g., a high eigenvector centrality indicated that a species has strong associations with other species which in turn had strong associations).

Hierarchical cluster analysis also was used to identify patterns of species associations (Minitab 18.1). Survey abundance data were first $\log (\mathrm{x}+1)$ transformed to minimize variation due to high abundances of some aggregating predators and the large number of zero values in the data set. Hierarchical agglomerative clustering using the Ward linkage and Pearson distance methods was used to minimize within cluster sum-of-squares and produce similar size clusters.

To assess whether the composition of mixed-species groups simply reflected the abundances of component species within the overall fish community, we used a two-sample $\mathrm{Z}$ test to compare sample proportions of abundances for the top 12 species observed in mixed-species groups. For this analysis we used species abundance data from this study and results from fish community surveys conducted in July-August 2013 as well as February and November 2014 (sampling approach and sites described in Alvarado et al., 2016; including unpublished community data from Bajo Alcyone, a site that was included in the present work). We used community data from this separate effort (i.e., a total of 345 transects covering $2.0 \mathrm{~km}^{2}$ area) as fish community surveys were logistically impractical to implement during the cruises reported here.

Foodweb 3D software v1.01 (Yoon et al., 2004) was used to organize the interconnected network of pair-wise species linkages within the behavior web independent of the number of occurrences (simply based on presence of a pair-wise relationship). This network was then used to examine how the structure of the behavior web changed (number of all pair-wise links) with simulated overfishing of five economically-valuable species chosen a priori as likely targets for hook fisheries (i.e., Caranx melampygus, Trianodon obesus, Dermatolepis dermatolepis, Caranx lugubris, and Bodianus diplotaenia). The removal of the entirety of interactions mediated by the target species (i.e., those interactions between target species as well as other species in the community) assumed overfishing to a state of local ecological extinction (i.e., where it can occur in isolated systems and those with low connectivity). The remaining number of pair-wise links was the response to this community level disturbance. This simulation involved a three-stage reduction in fish species 
from the current unfished state (i.e., removing the first two species from the list above, then the next, and finally the last two, with the order decided a priori based on assumed catchability). A best fit regression through the four points produced a model of the relationship of species richness within the network and complexity based on the number of pair-wise links within the web.

\section{Results}

Thirty-three species, or putative species (based on classification at a higher taxonomic level), were observed in 288 mixed-species hunting groups (Tab. 1). Group membership included seven non-piscivorous species that were either followed by, or joined with, piscivores to hunt and ambush prey disturbed by their activities. We concluded our sampling was adequate regarding the diversity of species involved in such group behaviors based on the asymptotic pattern in a species accumulation curve as well as results from Michaelis-Menton and Chao 1 estimators of total species richness (Fig. 2). Species richness and group size varied across observations. The mean species per group was 2.4 (median $=2.0$, range 2-6), while there was a mean of 8.1 individuals per group (median $=4.0$, range 2-80). Overall, mixed-species groups were primarily composed of species that combined morphologically-diverse forms, including those that could gain access to crevices (flexible and filiform; e.g., D. dermatolepis, T. obesus, Muraenidae spp.) and those that could rapidly pursue escaping prey (laterally flattened and fusiform; e.g., C. melampygus, C. lugubris). This pattern was consistent across the depth range of observations (Figs. 3-4).

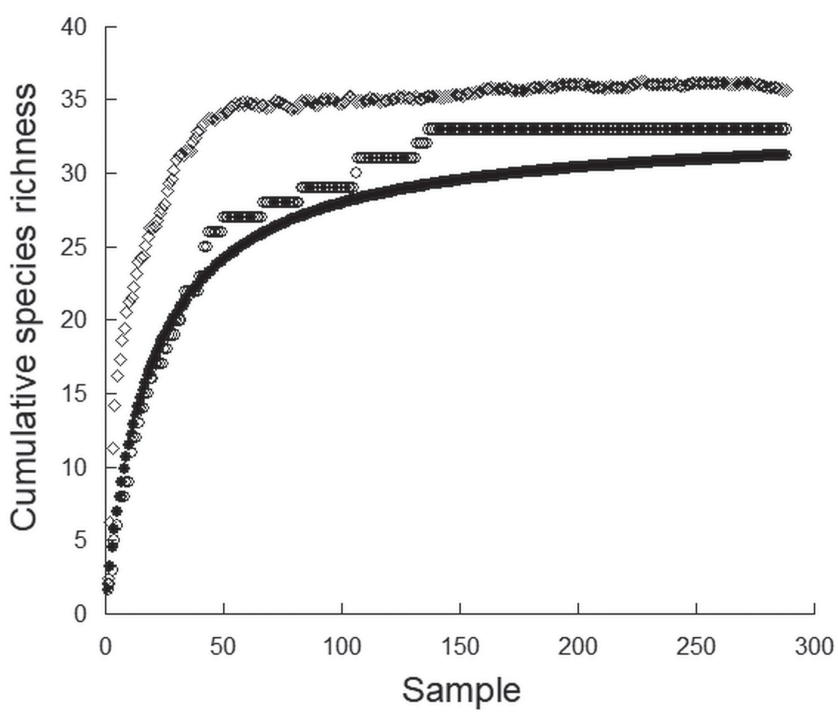

Fig. 2. Cumulative species richness based on consecutive samples (open circles) as well as Chao 1 (open diamonds) and Michaelis-Menton estimates of species richness (solid circles). Values calculated using Primer version 6.1.13 software.

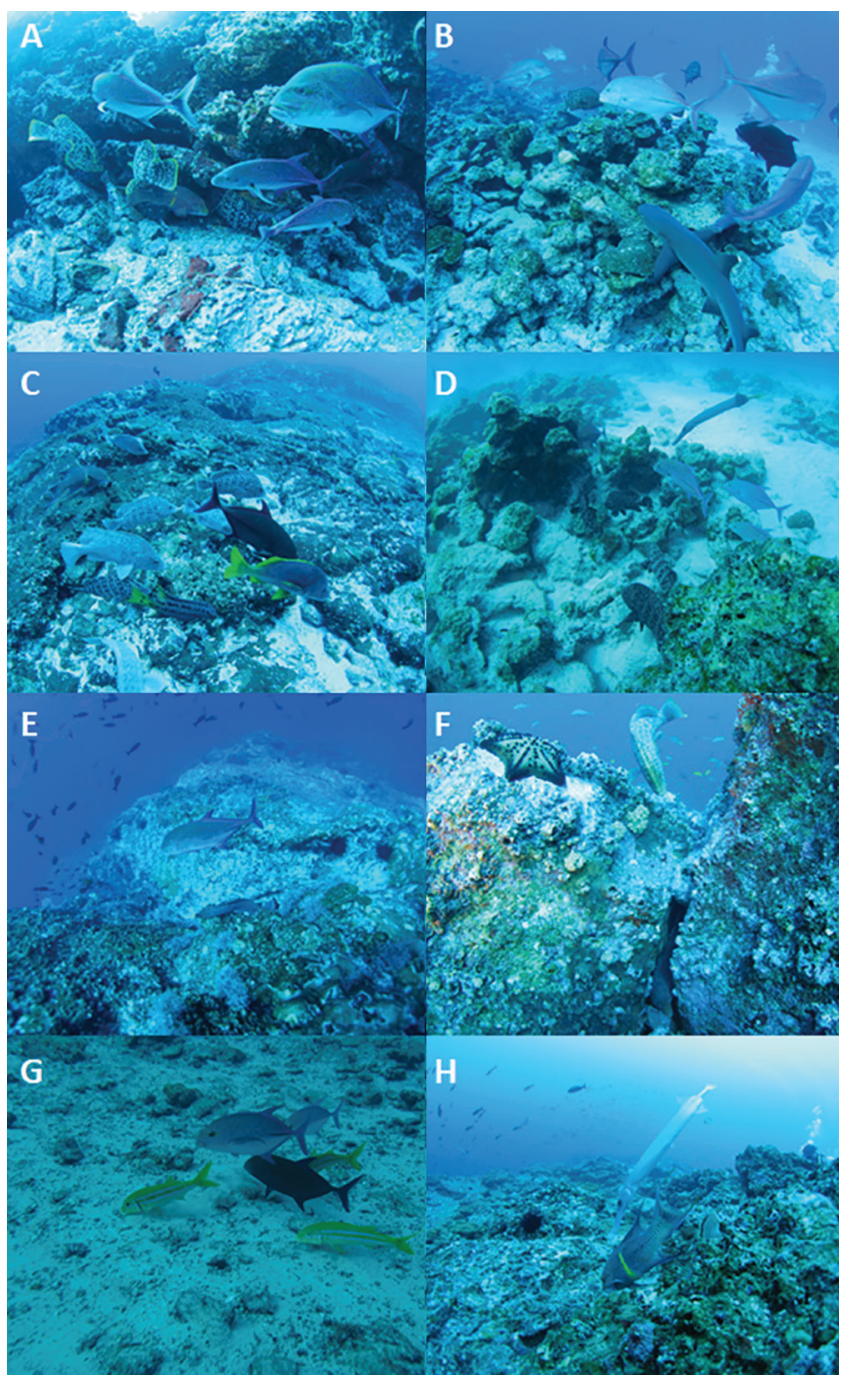

Fig. 3. Examples of mixed-species hunting groups observed to ca. $35 \mathrm{~m}$ depth. (A) Caranx melampygus, Dermatolepis dermatolepis and Bodianus diplotenia at a crevice. Note $D$. dermatolepis and $B$. diplotaenia are able to maneuver deep into the crevice while $C$. melampygus follow from above and search for escaping prey. (B) Group composed of C. melampygus, Trianodon obesus, Cephalopholis panamensis and unidentified muraenid eel (hidden within crevices) hunt for prey within crevices amongst coral and coral rubble along reef edge. (C) Lutjanus argentiventris, D. dermatolepis, $C$. melampygus and $B$. diplotaenia hunt for prey as group traverses low relief volcanic pavement along a pinnacle. (D) Group composed of D. dermatolepis, C. melampygus and Aulostomus chinensis. Note position of A. chinensis in lead over C. melampygus. (E) C. melampygus follows above a muraenid eel hunting within narrow crevices. (F) As in previous image, D. dermatolepis follows above muraenid eel hunting within narrow crevice. $(\mathrm{G})$ $C$. melampygus follow $B$. diplotaenia hunting over sand and volcanic rubble habitat. (H) $B$. diplotaenia and $A$. chinensis hunt in tandem along edge of pinnacle. 


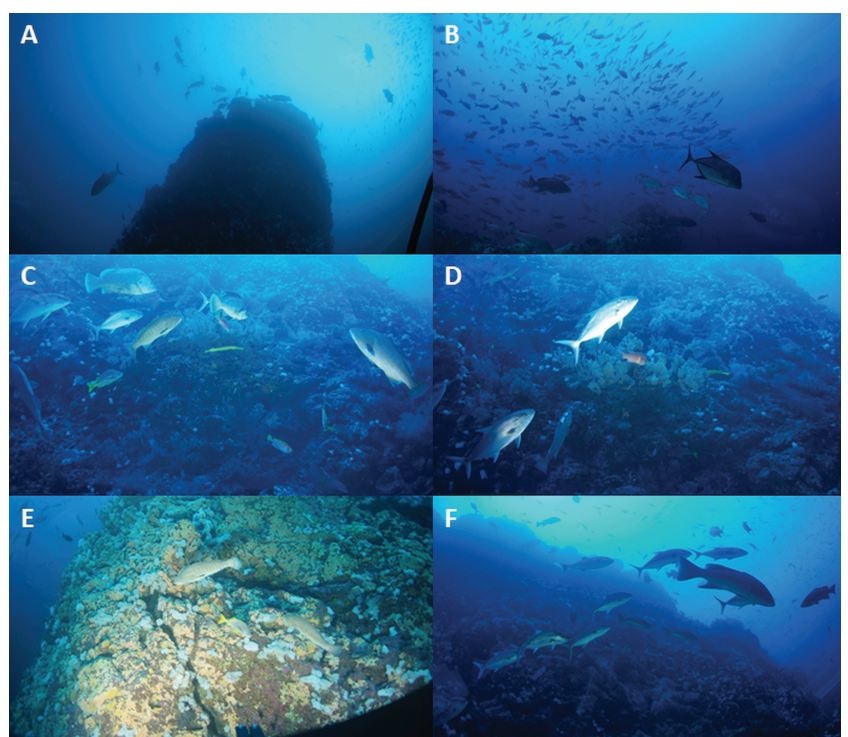

Fig. 4. Examples of mixed-species hunting groups from $c a$. 50-80 m depth at the Everest deep pinnacle site. (A) Caranx melampygus, Caranx lugubris, Mycteroperca olfax hunting in groups around the steep upper slope and peak, where smaller prey fish like Paranthias colonus aggregate in the water column. Periodic attacks by single fish and adjacent pairs were observed. (B) C. melampygus, C. lugubris and $M$. olfax move as a group but widely spaced in this setting. Individual fish attacked proximate prey that reacted to nearby predators. (C) Seriola rivoliana, D. dermatolepis, Lutjanus argentiventris, Bodianus diplotaenia and Aulostomus chinensis hunt for prey amongst corals and within crevices. (D) Image recorded soon after $\mathrm{C}$ (previous image) illustrating $D$. dermatolepis and B. diplotaenia entering, and A. chinensis emerging from a dense patch of corals to hunt while $S$. rivoliana maneuver above to encounter potential escaping prey. (E) M. olfax and L. argentiventris follow a moray eel (hidden within narrow crevice). (F) Large group of S. rivoliana and $M$. olfax move in tandem around the summit and upper slope, with occasional attacks by individuals on potential prey.

We found it noteworthy that $21.5 \%(\mathrm{n}=62)$ of events included direct observations of attacks on prey, and that behavioral precursors to attacks were consistent with the elements of predation-related behaviors as described above. Observation of attacks was difficult when predators were hunting along edges of complex seafloor habitats and within crevices, so this value is a minimum estimate of attacks. Confirmation of capture success was not possible from most observations due to angle and distance as well as rapid handling and ingestion of small prey.

Network visualization illustrated the variation between species pairs in the web of associations occurring in hunting groups (Fig. 5). Network metrics (Tab. 1) identified dominant species with highest connectivity across the network. All metrics consistently indicated that 10 species had the greatest degree of interactions within the network based on the pattern of the negative exponential distributions plotted on species organized by declining values of pair-wise links (Fig. 6). The top 10 species, occurring before the approximate position where values reach an asymptote, were $C$. melmpygus, D. dermatolepis, Aulostomus chinensis, Mycteroperca olfax, Bodianus diplotaenia, C. lugubris, Lutjanus viridis, Lutjanus argentiventris, Anisotremus interruptus and T. obesus. These 10 species accounted for $60 \%$ of pair-wise species interactions within the network. Fistularia commersonii and muraenidae spp. were just beyond the inflection point for network strength, and exhibited functional roles like similar, higher-ranked species. Specifically, F. commersonii was similar to $A$. chinensis as an ambush predator and species of muraenid eel hunted in crevices to an extent greater then $D$. dermatolepis and T. obesus. Balistidae spp., fifteenth in rank based on pair-wise links, had a much higher value of total occurrences in samples than species higher or lower on the ranked list. This taxon generally was observed foraging more in the open in a scan-and-pick foraging style (sensu Keenleyside, 1979), and served as a focal animal for followers seeking prey flushed by the activity. Fifty-four percent of all species (18 of 33) in this mixed-species behavior web also aggregated in single-species groups with $80 \%$ of the ten dominant species exhibiting this same pattern of cooperative behaviors among conspecifics. Such behavior is indicative of a cooperative group hunting (foraging) repertoire within each species.

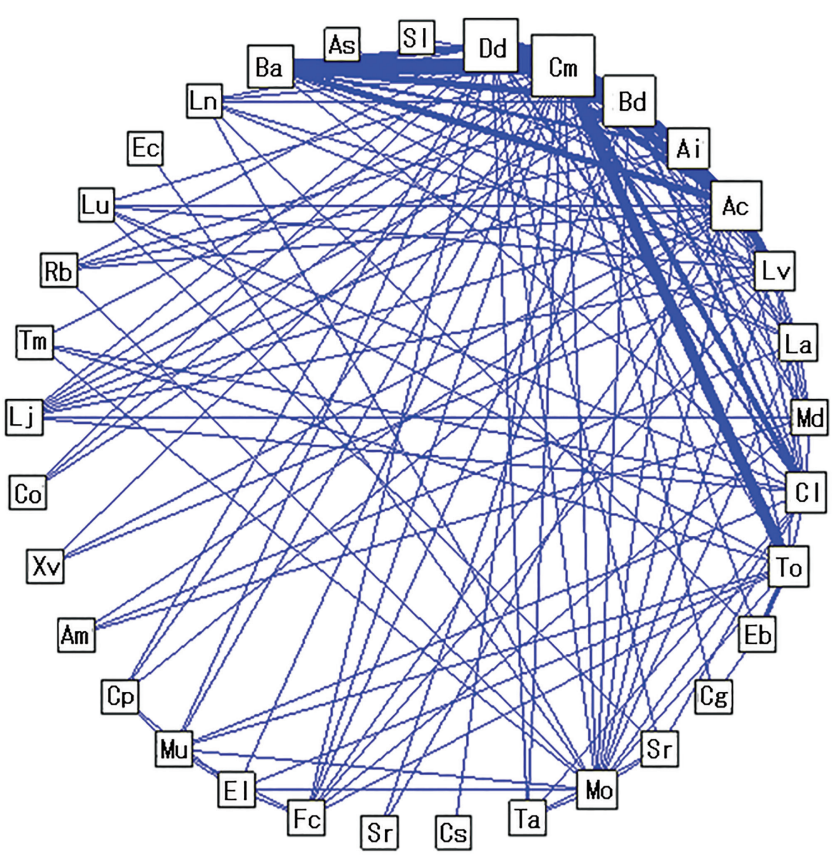

Fig. 5. Network visualization of the web of associations between species ( 33 species with 288 pair-wise links). The size of each species node is weighted relative to the frequency of each species in any group (abbreviations for each species are defined in Tab. 1). The lines between species nodes are weighted by the relative frequency of associations between each species pair. 


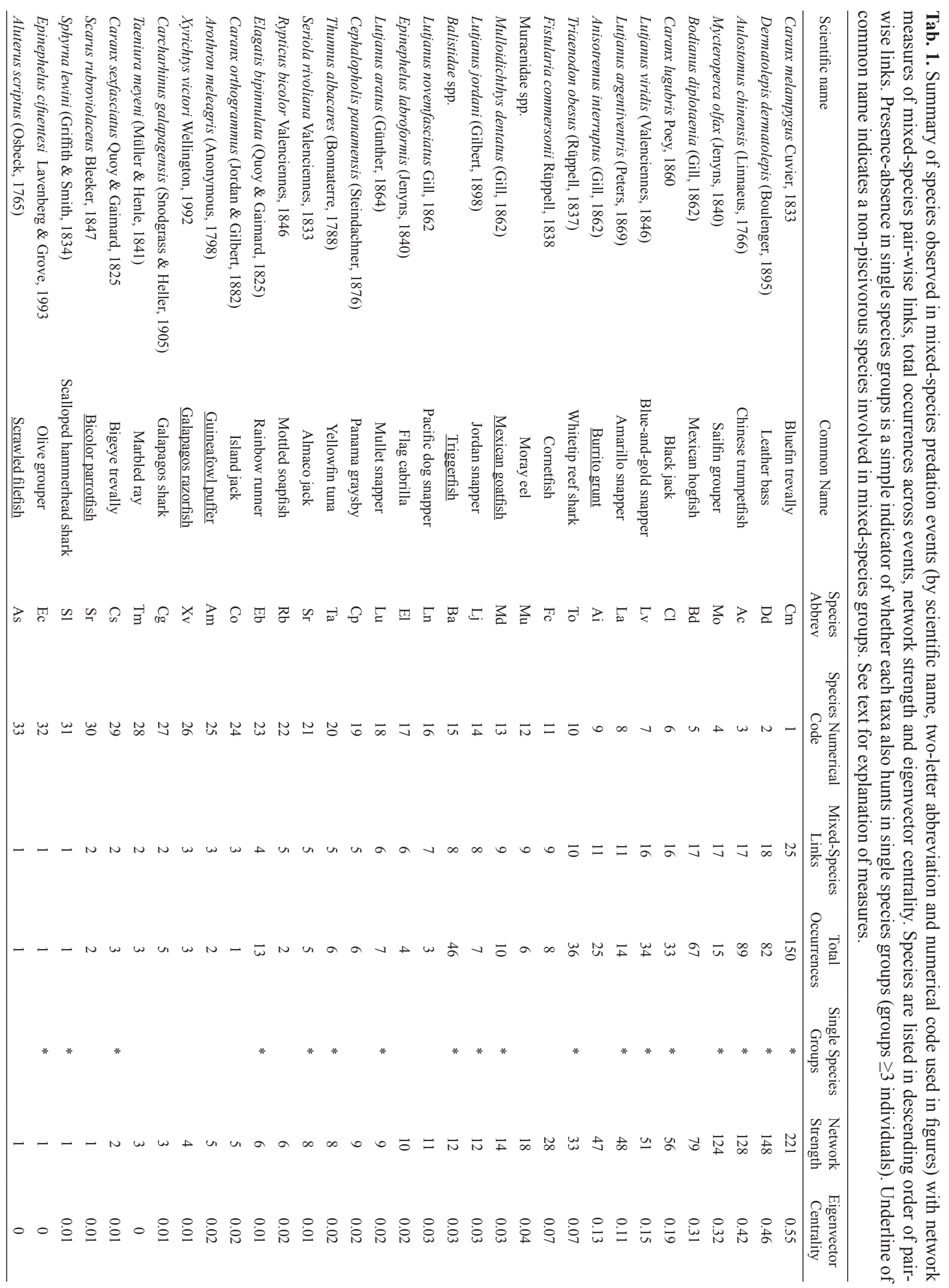




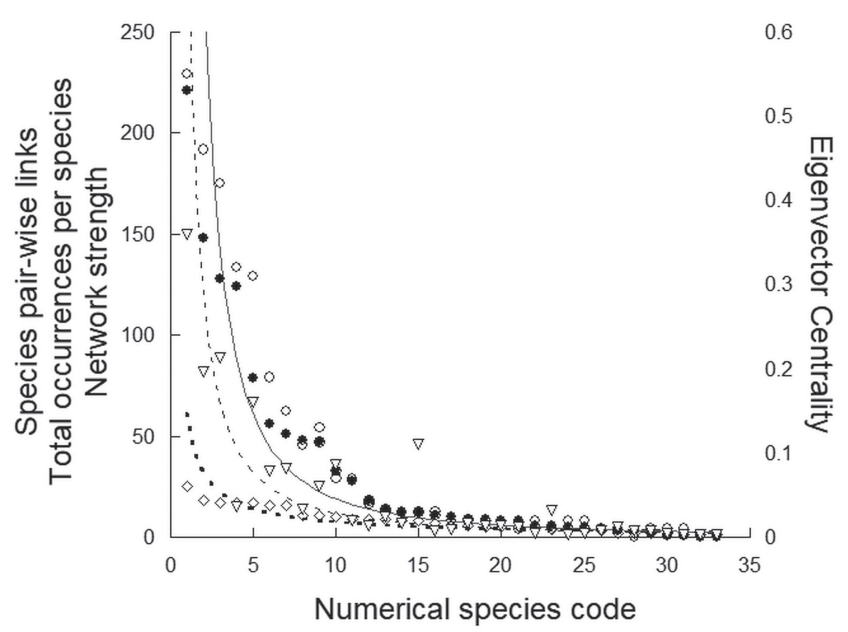

Fig. 6. Relationships between three metrics of network connectivity in order to identify important species within the behavior web (species pair-wise links $=$ open diamond and dotted line, total occurrences per species $=$ open triangle and dashed line, network strength $=$ solid circle and solid line). Species on $\mathrm{x}$-axis in descending order based on value of pair-wise links (as in Tab. 1). Regression lines are based on the power function. Eigenvector centrality values (open circle) plotted for comparison.

Cluster analysis (Fig. 7) identified a cluster of associations for eight of the ten dominant species identified by the network metrics (i.e., in cluster 1). Significantly, there were two distinct clusters linked at larger distances. This pattern is generally consistent with the strength of pair-wise linkages for dominant species in the network diagram (Fig. 6), where piscivores did not form unique groupings, but those dominant species were joined by a diversity of taxa from the pool of local piscivores (i.e., those in cluster 2). The presence of Balistidae spp. and Elegatis bipinnulata in cluster 1 is indicative of the strong associations with the dominant interacting species, despite low to moderate numbers of occurrences.

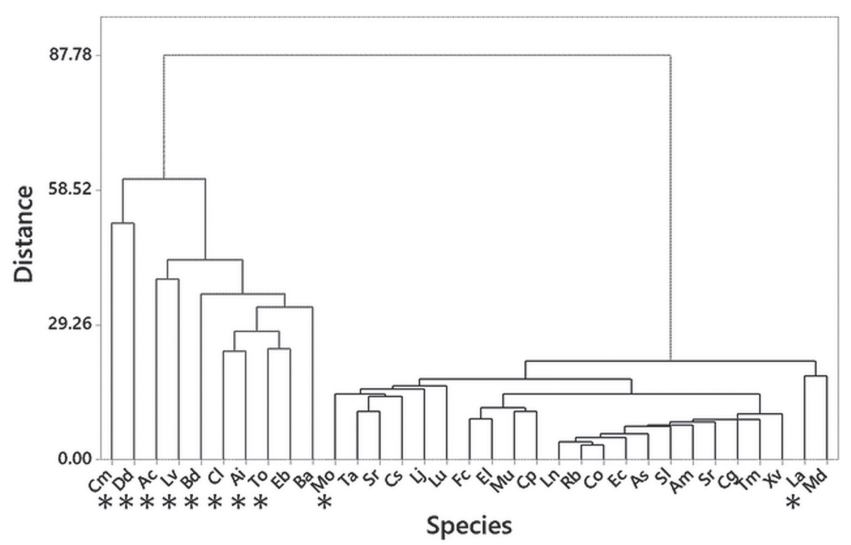

Fig. 7. Cluster analysis of species co-occurrences in groups based on the Ward linkage method and Pearson distance. Abbreviations for each species are defined in Tab. 1. Note two dominant clusters (cluster 1 at left and cluster 2 at right). An asterisk below species codes indicate membership in top 10 species based on mixed-species links.
The composition of mixed-species groups did not reflect the relative abundances of their component species within the overall community of fishes, suggesting that group membership was an elective choice by individuals (Tab. 2). Comparison of the top 12 species in mixed-species hunting groups with their proportional abundance from the overall community resulted in 11 of 12 as significantly different ( $Z$-statistic) at $p<0.05$ level. While there is a lack of independence based on use of proportional data, this test is unlike a Chi-square test of proportionality as tests for each species yield species-specific results.

Tab. 2. Results of two sample $\mathrm{Z}$ test to compare proportions of abundances for the top 12 species observed in mixedspecies groups with those from fish community surveys (see text for details).

\begin{tabular}{lcccc}
\hline \multicolumn{1}{c}{ Species } & $\begin{array}{c}\text { Proportion } \\
\text { Community }\end{array}$ & $\begin{array}{c}\text { Proportion } \\
\text { Groups }\end{array}$ & Z statistic & $\mathrm{P}<$ \\
\hline Caranx melampygus & 0.0349 & 0.2201 & 34.594 & 0.01 \\
Dermatolepis dermatolepis & 0.0127 & 0.1959 & 46.509 & 0.01 \\
Aulostomus chinensis & 0.0159 & 0.0598 & 12.794 & 0.01 \\
Mycteroperca olfax & 0.0015 & 0.0118 & 8.643 & 0.01 \\
Bodianus diplotaenia & 0.0131 & 0.0533 & 12.822 & 0.01 \\
Caranx lugubris & 0.0013 & 0.0289 & 19.449 & 0.01 \\
Lutjanus viridis & 0.7988 & 0.3384 & -43.141 & 0.01 \\
Lutjanus argentiventris & 0.0138 & 0.0118 & -0.661 & $\mathrm{NS}$ \\
Triaenodon obesus & 0.0173 & 0.0431 & 7.529 & 0.01 \\
Fistularia commersonii & 0.0018 & 0.0047 & 2.606 & 0.01 \\
Muraenidae spp. & 0.0013 & 0.0035 & 2.220 & 0.05 \\
Lutjanus jordani & 0.0884 & 0.0284 & -8.572 & 0.01 \\
\hline
\end{tabular}

The sequential removal of species to simulate fishing effects on the pair-wise behavioral interaction web produced notable results. The unimpacted status quo (33 species with 282 pair-wise links) was followed first by the removal of C. melampygus and T. obesus (reducing the web to 31 species with 208 pair-wise links), followed by the removal of $D$. dermatolepis (30 species remaining with 174 links), and then C. lugubris and B. diplotaenia (28 species remaining with 122 pair-wise links). The removal of only five species produced a steep decline in species linkages plotted on richness (Fig. 8), albeit based on dominant species and the strong role they play in interactions across the web.

\section{Discussion}

Our results demonstrate that collective behaviors in mixed-species hunting groups of piscivorous fishes exhibited consistent patterns of associations for a set of dominant species and were common to this functional guild within the shallow fish community at Isla del Coco. This work demonstrates the utility of using coupled field observations and network approaches for quantifying the attributes of facilitative behavioral interactions within a particular trophic guild of animals, rather than using food web data alone 


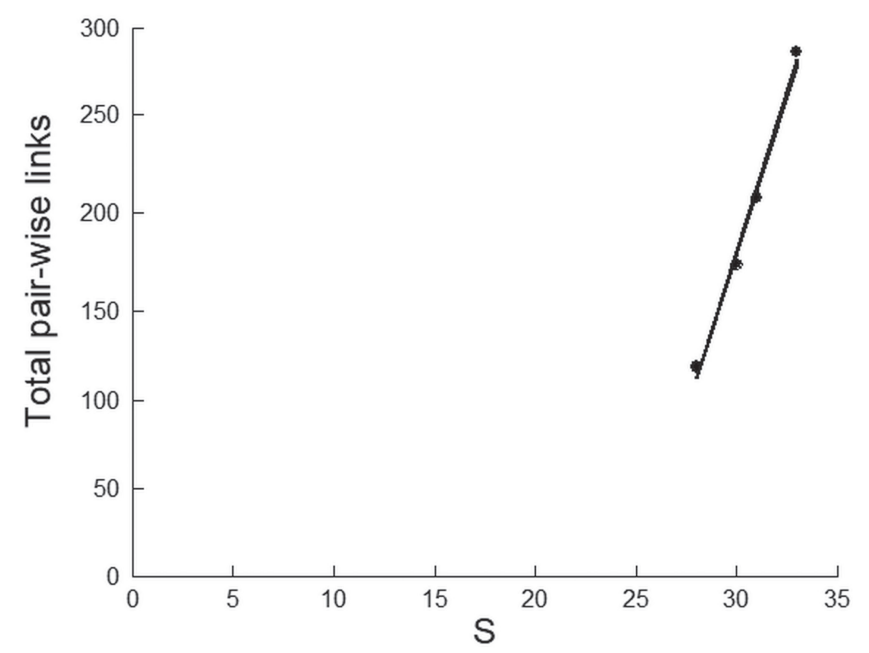

Fig. 8. Linear regression of total pair-wise links in the behavior web on species richness (links $=-781.8+32.08 \mathrm{~S} ; \mathrm{r} 2=$ 99.1 ) based on fisheries removal simulation. Noteworthy is the rapid decline in linkages within the behavior web with removal of only several key species. The reduction in species richness is with the sequential removal of first Caranx melampygus and Trianodon obesus, then Dermatolepis dermatolepis, Caranx lugubris and Bodianus diplotaenia from the data set in this study (see text for detailed explanation).

(e.g., Bascompte et al., 2005). Further, while the quantitative aspects of collective behavior between piscivores have been reported from other regions (Bshary et al., 2006), this study is one of few addressing such interactions at the guild level (but see Auster et al., 2013).

It was noteworthy that the behavioral associations between the diversity of species in the guild were tightly linked to a principal set of 10 dominant species within the network. This pattern indicated that this subset of the diversity within the piscivore guild played an overarching role in mediating the dynamics of these types of facilitative mixed-species interactions. The general pattern of agreement in the relative values of associations between species, revealed across the different quantitative metrics, suggested that multiple measures can be used to assess and verify the functional role each species plays within the guild by engaging in these types of interactions. Such assessments, based on behavioral network metrics, can aid in the identification of ecologically important species that can serve as targets for more detailed study, monitoring, and management attention (Jordán et al., 2008). Such quantitative indices also provide a set of measures for this marine protected area that can be used to compare the status of behavioral webs over time, both within and between habitats, and at other protected sites. Contrasts between communities in protected areas and those exploited by fishing, or impacted by other human-caused disturbances, can serve as natural experiments to improve our understanding of these types of species interactions.

The rationale for our fundamental descriptive approach was to provide a foundation for future studies to focus on assemblages or guilds with strong facilitative behaviors, to address and identify the potential for asymmetric responses of impacts to populations and communities. Identifying whether there are limits or rules that govern the scope of these types of interactions will be important for applying what is found in particular settings (i.e., communities, landscapes, habitats) over time and in other places. In this case we find that measures of species richness and group size per event at Isla del Coco were comparable to those observed for mixed-species groups of piscivores at minimally impacted (but not fully protected) sub-tropical reef sites in the western North Atlantic (Auster et al., 2013).

Further, results from this study were similar to those from sub-tropical reefs in the western Atlantic and Gulf of Mexico, with an apparent degree of redundancy in the piscivore guild and a subset of species that act as strong interactors within the behavior web (Auster et al., 2013). Morphological variation within groups also appeared to be a common element structuring group composition (e.g., Auster et al., 2016). However, with such limited sets of observations from other sites for comparison, we could only hypothesize that there were factors that constrained richness, group size, and composition for species in this trophic guild (e.g., Sih et al., 1998). There is a clear potential for interference competition between species with similar sizes, morphologies and hunting tactics in regard to finding and capturing prey. Indeed, local density of functionally similar predators may limit the trade-offs in energetic costs and benefits in terms of joining and leaving hunting groups (e.g., Kelley et al., 2011; Firth et al., 2015). Whether such patterns in richness and group size are conservative ecological properties in unimpacted communities remains to be determined. Yet if these types of ecological limits are widespread, they can serve as reference points to aid in assessments of community state and time-series monitoring. For example, richness in mixed-species hunting groups and patterns of group size were significantly reduced when compared to more heavily fished reef sites in the Gulf of Mexico (Auster et al., 2013).

The simulation of overfishing by eliminating five dominant but economically valuable species from the behavior web produced a rapid rate of decline $(53 \%)$ in pair-wise mixed-species interactions. Despite the coarse approach to addressing this question, we suggest the results can be used as a foundation to develop hypotheses to be tested via observation in fish communities along a gradient of fishing pressure. Indeed, this pattern suggests the potential for a rapid decline in the role behavioral facilitation of hunting can play in a fish community subject to overexploitation and a potential cascade of population and community-level effects (e.g., enhanced survival and expansion of meso-predator and lower trophic level species; Stallings, 2008). Of course, this simulated response assumes that remaining species will not exhibit any form of behavioral compensation (e.g., switching of pair-wise species association, release from behavioral constraints of functionally similar predators; scenarios that are testable in future studies). 
All group hunting observations occurred over the time scale of minutes, with some groups forming and dispersing within the time-frame of observation $(<10 \mathrm{~min})$ while others moved into or out of the field of view within that time. In all cases this facilitation of predation was temporary and not on the same time scale as classic mutualisms that play out over the lifetime of the animals involved (e.g., anemone and anemone-fish relationships), although we were not able to develop time budgets for patterns of group membership. Two key aspects of group formation have yet to be resolved. First, the cues used by individuals to initiate the synchronization of behavior remain unknown (Vail et al., 2013). Some form of information transfer involved in coalescing groups could involve visual cues related to search behavior, acoustic cues produced by hunting-foraging behavior (e.g., jaw and fin movements, bites), chemical cues produced from previous activities (e.g., from consumption of prey), or some combination. Overall mixed-species groups at Isla del Coco appeared to fit multiple classes of associations (sensu Lukoschek, McCormick, 2002): inter-specific group hunting, following and scavenging, and hunting by riding models of attendant associations. Second, individuals must assess the energetic costs and benefits of group membership as related to timing of joining a group and subsequent departure. This could also involve prior experience of individuals with alternative tactics related to predation success (Matsuda et al., 1993) or simply an individual's state of satiation. Issues of change in shelter resources and perceived risk of predation by prey also could play a role in the time investment in group hunting behaviors (Bshary et al., 2007). Identifying the behavioral roles of individuals and their predation success rates within groups may shed light on how mixed-species hunting groups are formed and under what conditions.

The primary ecological observations reported here suggest multiple avenues for inquiry. Growth, maturation, and fecundity are fundamentally based on hunting success and energy intake, survivorship based on predator avoidance, and patterns of distribution based on density dependent behavioral interactions, among others. While predator-prey interactions, primarily derived from gut content studies, have been fundamental in quantifying multi-species interactions and the flow of energy derived via prey consumption in marine communities, the bioenergetic trade-offs of collective behavior remain to be evaluated. For example, as prey populations vary in abundance and distribution (e.g., based on variation in attributes of habitat), behavioral interactions amongst predators may change (i.e., exhibiting context dependency; Bronstein, 1994) either regarding the structure of pair-wise associations or the intensity (frequency) of those associations. Indeed, periodic spawning aggregations of prey fishes can provide a unique trophic subsidy to predators (Mourier et al., 2016) and influence the interactions within predator behavior webs. Here we provided an example to establish a fundamental structure for beginning to address such issues. The current literature provides tantalizing examples of the role such interactions might play in the wider context of conservation and sustainable use, but more detailed studies over appropriate space and time scales are needed (Hay et al., 2004; Bronstein, 2015). That is, our understanding of the roles such interactions play in regulating populations and communities remain substantially limited. Linking knowledge of variation in behavioral interactions to bioenergetics and ultimately to demographic consequences in fish populations will be the key to linking behavior to conservation and management.

\section{Acknowledgments}

The authors gratefully acknowledge the support and encouragement of the Undersea Hunter Group, the captains and crews of MV Sea Hunter and MV Argo, the divemasters and smallboat operators that made diving operations safe and productive, and the pilots and crews of the DeepSee submersible that took us beyond the limits of wet diving. Isla del Coco National Park kindly provided permits for our research (ACMIC-1-2015-002). UCR supported travel for PJA as a visiting scholar and facilitated the work with JC that led to the present study. Randy Rudd and Barbara Phillips provided expert assistance in the field and collected behavioral data during the 2015 cruise. Comments on an earlier draft of this manuscript by Christian Conroy and those by two anonymous reviewers greatly improved our presentation of results.

\section{References}

Alvarado JJ, Beita-Jiménez A, Mena S, Fernández-García C, Guzman-Mora AG, Cortés J. Ecosistemas coralinos del Parque Nacional Isla del Coco, Costa Rica: estructura y comparación 1987-2014. Rev Biol Trop. 2016; 64(Suppl 1):S153-S175.

Auster PJ, Kracker L, Price V, Heupel E, McFall G, Grenda D. Behavior webs of piscivores at subtropical live-bottom reefs. Bull Mar Sci. 2013; 89(1):377-96.

Auster PJ, Lindholm J. Pattern in the local diversity of coral reef fishes versus rates of social foraging. Caribb J Sci. 2002; 38(3-4):263-66.

Auster PJ, Lindholm J. Variation in social foraging by fishes across a coral reef landscape. Proceedings of the 11th International Coral Reef Symposium. ICRS Conference Proceedings. 2008; 1:286-90.

Auster PJ, Sánchez-Jiménez A, Rodríguez-Arrieta JA, Quesada AJ, Pérez C, Naranjo-Elizondo B, Blum S, Cortés J. Facilitative behavioral interactions between deepwater piscivores at Isla de Coco National Park and Las Gemelas Seamount, Costa Rica. Rev Biol Trop. 2016; 64(Suppl 1):187-96.

Barrat A, Barthélemy M, Pastor-Satorras R, Vespignani A. The architecture of complex weighted networks. Proc Natl Acad Sci USA. 2004; 101(11):3747-52.

Bascompte J, Melián CJ, Sala E. Interaction strength combinations and the overfishing of a marine food web. Proc Natl Acad Sci USA. 2005; 102(15):5443-47. 
Berger-Tal O, Polak T, Oron A, Lubin Y, Kotler BP, Saltz D. Integrating animal behavior and conservation biology: a conceptual framework. Behav Ecol. 2011; 22(2):236-39.

Bronstein JL. Conditional outcomes in mutualistic interactions. Trends Ecol Evol. 1994; 9(6):214-47.

Bronstein J, editor. Mutualism. Oxford: Oxford University Press; 2015.

Bruno JF, Stachowicz JJ, Bertness MD. Inclusion of facilitation into ecological theory. Trends Ecol Evol. 2003; 18(3):119-25.

Bshary R, Hohner A, Ait-el-Djoudi K., Fricke H. Interspecific communicative and coordinated hunting between groupers and giant moray eels in the Red Sea. PLoS Biol. 2006; 4(12):e431. Available from: https://doi.org/10.1371/journal. pbio.0040431

Bshary R, Salwiczek L, Wickler W. Social cognition in nonprimates. In: Dunbar RIM, Barrett LS, editors. Oxford handbook of evolutionary psychology. Oxford: Oxford University Press; 2007. p.83-101.

Clarke KR, Gorley RN. PRIMER v6: User Manual/Tutorial. PRIMER-E, Plymouth; 2006.

Clarke KR, Warwick RM. Change in marine communities: an approach to statistical analysis and interpretation, 2nd ed. Plymouth: PRIMER-E; 2001.

Connor RC. The benefits of mutualism: a conceptual framework. Biol Rev. 1995; 70(3):427-57.

Cortés J. Isla del Coco: Coastal and marine ecosystems. In: Kappelle M, editor. Costa Rican Ecosystems. Chicago and London: University of Chicago Press; 2016. p.162-191.

Cortés J, Blum S. Life to $450 \mathrm{~m}$ depth at Isla del Coco, Costa Rica. Rev Biol Trop. 2008; 56(Suppl 2):189-206.

Dickman CR. Commensal and mutualistic interactions among terrestrial vertebrates. Trends Ecol Evol. 1992; 7(6):194-97.

Estes JA, Terborgh J, Brashares JS, Power ME, Berger J, Bond WJ, Carpenter SR, Essington TE, Holt RD, Jackson JBC, Marquis RJ, Oksanen L, Oksanen T, Paine RT, Pikitch EK, Ripple WJ, Sandin SA, Scheffer M, Schoener TW, Shurin JB, Sinclair AR, Soulé ME, Virtanen R, Wardle DA. Trophic downgrading of planet Earth. Science. 2011; 333(6040):301-06.

Firth JA, Voelkl B, Farine DR, Sheldon BC. Experimental evidence that social relationships determine individual foraging behavior. Curr Biol. 2015; 25(23):3138-43.

Friedlander AM, Zgliczynski BJ, Ballesteros E, Aburto-Oropeza $\mathrm{O}$, Bolaños A, Sala E. The shallow-water fish assemblage of Isla del Coco National Park, Costa Rica: structure and patterns in an isolated, predator-dominated ecosystem. Rev Biol Trop. 2012; 60 (Suppl 3):321-38.

Hay ME, Parker JD, Burkepile DE, Caudill CC, Wilson AE, Hallinan ZP, Chequer AD. Mutualisms and aquatic community structure: the enemy of my enemy is my friend. Annu Rev Ecol Evol S. 2004; 35(1):175-97.

Hebshi AJ, Duffy DC, Hyrenbach KD. Associations between seabirds and subsurface predators around Oahu, Hawaii. Aquat Biol. 2008; 4:89-98.

Heithaus MR, Frid A, Wirsing AJ, Worm B. Predicting ecological consequences of marine top predator declines. Trends Ecol Evol. 2008; 23(4):202-10.
Hobson ES. Predatory behavior of some shore fishes in the Gulf of California. Research Report U.S. Fish \& Wildlife Service. 1968; 73:1-92.

Jordán F, Okey TA, Bauer B, Libralato S. Identifying important species: linking structure and function in ecological networks. Ecol Model. 2008; 216(1):75-80.

Keenleyside MHA. Diversity and adaptation in fish behaviour. Berlin: Springer-Verlag; 1979. (Zoophysiology; vol 11).

Kelley JL, Morrell LJ, Inskip C, Krause J, Croft DP. Predation risk shapes social networks in fission-fusion populations. PLoS ONE. 2011; 6(8):e24280. Available from: https://doi. org/10.1371/journal.pone.0024280

Krause J, Ruxton GD. Living in groups. Oxford: Oxford University Press; 2002. (Oxford series in ecology and evolution).

Lima SL. Putting predators back into behavioral predator-prey interactions. Trends Ecol Evol. 2002; 17(2):70-75.

Lukoschek V, McCormick MIA. A review of multi-species foraging associations in fishes and their ecological significance. In: Moosa MK, Soemodihardjo S, Soegiarto A, Romimohtarto K, Nontji A, editors, Proceedings of the 9th International Coral Reef Symposium, Bali. International Society for Reef Studies; 2002. p.467-74.

MacNulty DR, Mech LD, Smith DW. A proposed ethogram of large-carnivore predatory behavior, exemplified by the wolf. J Mammal. 2007; 88(3):595-605.

Matsuda H, Abrams PA, Hori M. The effect of adaptive antipredator behavior on exploitative competition and mutualism between predators. Oikos. 1993; 68(3):549-59.

Mourier J, Maynard J, Parravicini V, Ballesta L, Clua E, Domeier ML, Planes S. Extreme inverted trophic pyramid of reef sharks supported by spawning groupers. Curr Biol. 2016; 26(15):2011-2016

O'Connor NE, Bruno JF. Predatory fish loss affects the structure and functioning of a model marine food web. Oikos. 2007; 116(12):2027-38.

Overholtzer KL, Motta PJ. Effects of mixed-species foraging groups on the feeding and aggression of juvenile parrotfishes. Environ Biol Fishes. 2000; 58(3):345-54.

Pitcher TJ, Parrish JK. Functions of shoaling behaviour in teleosts. In: Pitcher TJ, editor. Behaviour of Teleost Fishes. 2nd ed. London: Chapman \& Hall; 1993. pp.363-439.

Sandin SA, Smith JE, DeMartini EE, Dinsdale EA, Donner SD, Friedlander AM, Konotchick T, Malay M, Maragos JE, Obura D, Pantos O, Paulay G, Richie M, Rohwer F, Schroeder RE, Walsh S, Jackson JBC, Knowlton N, Sala E. Baselines and degradation of coral reefs in the Northern Line Islands. PLoS ONE. 2008; 3(2):e1548. Available from: https://doi. org/10.1371/journal.pone.0001548

Sazima C, Guimarães PR, Dos Reis SF, Sazima I. What makes a species central in a cleaning mutualism network? Oikos. 2010; 119(8):1319-25.

Schmitt EF, Sullivan KM. Analysis of a volunteer method for collecting fish presence and abundance data in the Florida Keys. Bull Mar Sci. 1996; 59(2):404-16.

Sih A, Englund G, Wooster D. Emergent impacts of multiple predators on prey. Trends Ecol Evol. 1998; 13(9):350-55. 
Stachowicz JJ. Mutualism, facilitation, and the structure of ecological communities: positive interactions play a critical, but underappreciated, role in ecological communities by reducing physical or biotic stresses in existing habitats and by creating new habitats on which many species depend. BioScience. 2001; 51(3):235-46.

Stallings CD. Indirect effects of an exploited predator on recruitment of coral-reef fishes. Ecology. 2008; 89(8):2090-95.

Starr RM, Green K, Sala E. Deepwater fish assemblages at Isla del Coco National Park and Las Gemelas Seamount, Costa Rica. Rev Biol Trop. 2012; 60 (Suppl 3):347-62.

Sumpter DJT. Collective animal behavior. Princeton: Princeton University Press; 2010.

Vail AL, Manica A, Bshary R. Referential gestures in fish collaborative hunting. Nat Commun. 2013; 4:1765 Available from: https://doi.org/10.1038/ncomms2781
Whitehead H. SOCPROG programs: analyzing animal social structures. Behav Ecol Sociobiol. 2009; 63(5):765-78.

Yoon I, Williams RJ, Levine E, Yoon S, Dunne JA, Martinez ND. 2004. Webs on the Web (WoW): 3D visualization of ecological networks on the WWW for collaborative research and education. Proceedings SPIE 5295, Visualization and Data Analysis 5295:124-132. Available from: https://doi. org/10.1117/12.526956.

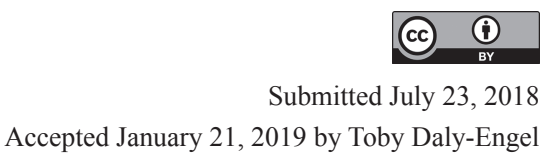


